(This is a final draft, if you would like to cite this paper please cite the final version housed here: http://goo.gl/lEjHjH )

\title{
Change Your Look, Change Your Luck: $\underline{\text { Religious Self-Transformation and Brute Luck Egalitarianism }}{ }^{1}$
}

\begin{abstract}
My intention in this paper is to reframe the practice of veiling as an embodied practice of self-development and self-transformation. I argue that practices like these cannot be handled by the choice/chance distinction relied on by those who would restrict religious minority accommodations. Embodied self-transformation necessarily means a change in personal identity and this means the religious believer cannot know if they will need religious accommodation when they begin their journey of piety. Even some luck egalitarians would find leaning exclusively on preference and choice to find who should be burdened with paying the full costs of certain choices in one's life too morally harsh to be justifiable. I end by briefly illustrating an alternative way to think about religious accommodation that does not rely on the choice/chance distinction.
\end{abstract}

In Québec, at the end of 2013 and start of 2014, the then elected separatist party proposed a bill initially called the "Québec Charter of Values." It would have effectively banned religious symbols such as all forms of the Islamic veil, the Sikh turban, the Jewish kippah, large crosses, and other "conspicuous"2 religious symbols from being worn by public servants. A constant question that showed up in the discourse surrounding the charter was why some minorities received exceptions from laws and some did not. One justification for differentiating between who got exemptions and who did not was that certain minorities, such as the disabled, were unfortunate in that they had not chosen their disability and therefore deserved accommodation. On the other hand, religious people chose their religion and the form their religious practice takes and therefore needed no accommodation but should conform like everyone else to general laws. These questions of fortune and misfortune also showed up in discourse around the French ban on

\footnotetext{
${ }^{1}$ Acknowledgements: I would like to thank Alia Al-Saji and Daniel Weinstock for their patience in going through earlier drafts as well as pushing me conceptually. I would also like to thank Douglas Hanes for coming up with the title of the paper.
} 
the veil and bans proposed for religious animal slaughter in Denmark. ${ }^{3}$ Specifically in townhall meetings that Charles Taylor and Gerard Bouchard conducted in Québec to get a sense of the public's opinions on how minorities in Québec were to be handled, this theme was present:

During our consultations, a number of participants called into question the legitimacy of accommodation requests for religious reasons. The rightfulness of an adjustment that allows, for example, a female or a male student to wear a headscarf or a kirpan, respectively, is not obvious to everyone. Similar exemptions may be granted for health reasons: a young girl must cover her head on her physician's orders or a diabetic child must bring a syringe and a needle to school. No one would dream of objecting to such exceptions. We also know that accommodation aimed at ensuring the equality of pregnant women or the physically disabled is readily accepted. Québec (and Western) public opinion thus reacts much more harshly to requests motivated by religious belief. One of the most frequent arguments put forward to explain why requests justified by religious reasons and those motivated by health reasons cannot be put on an equal footing is that individuals who are disabled or sick have not chosen their condition while believers appear to have a choice between renouncing their religion or reinterpreting it in a manner that makes accommodation requests superfluous. (2008, 143, emphasis added)

This position, linking accommodation and choice, can be found represented in a particular branch of anglo-american political philosophy called "Luck Egalitarianism." Although often linked only to just distribution patterns rather than the issue of minority religious accommodation, it has, since the 1970 s, become a sophisticated position that attempts to appeal to both the left and the right by being egalitarian yet also sensitive to responsibility. To many liberals it seems intuitively right that a gambler who squandered all their money should have a weaker entitlement to claim benefits than someone who was born into poverty. The reason for this is that the gambler is presumably more responsible for their own deprivation. To Richard Arneson, responsibility plays a fairly straightforward regulatory role in shaping people's entitlements. If someone is responsible for their own deprivation then they and not anyone else should suffer the burdens associated with that deprivation, otherwise "some individuals [who] 
behave culpably irresponsibly, again and again, [will end up] draining resources that should go to other members of society" (Arneson 2000, 349).

My intention is to reframe the practice of veiling as an embodied practice of selfdevelopment and self-transformation and argue that practices like these cannot be handled by the choice/chance distinction. Embodied self-transformation necessarily means a change in personal identity and this means the religious believer cannot know if they will need religious accommodation when they begin their journey of piety. Even some luck egalitarians would find leaning exclusively on preference and choice to find who should be burdened with paying the full costs of certain choices in one's life too morally harsh to be justifiable. I end by briefly illustrating an alternative way to think about religious accommodation that does not rely the choice/chance distinction.

It must be emphasized that my goal here is not to undermine all luck egalitarian positions; my aim here is to attack the popular intuition that the distinction between chance and choice is morally relevant to broad debates about multiculturalism as a normative ideal and minority religious accommodation. Along with becoming more sophisticated, luck egalitarianism has multiplied into a spectrum of philosophical positions. Many of these positions will not be touched by my argument either because some argue that luck egalitarianism only applies to economic, distributive justice (Tan 2008, 670), while some others rely on the choice/chance distinction in talking about minority accommodations but think that strong valuation choices are not choices but chance (Cohen 2004) and finally some luck egalitarians think that religious practices are choices, yet luck egalitarianism should be considered a pro tanto theory that can be overruled by other values, such as burdens that are too costly (Tomlin 2013, Knight 2009). We 
will come back to this third position later when dealing with the criticism that people should be responsible for actions that they identify with.

The view my argument wishes to reach are those that embody best the intuition illustrated by those in the Québec town hall meetings. This view Peter Vallentyne calls Brute luck egalitarianism $(2008,58)$ and Patrick Tomlin calls 'canonical' luck egalitarianism ${ }^{4}(2013,395)$. This view holds simply that those states and events that the agent could not deliberately influence should be equalized or accommodated but that the effects that are attributable to the agent's choice $^{5}$ need not be (Vallentyne 2008, 58). ${ }^{6}$

My critique then is not just of this one luck egalitarian view, but also strong responsibility-sensitive views of equal opportunity such as Dworkin and also Brian Barry. ${ }^{7}$ In a section of Barry's book Culture and Equality, he gives a sustained argument against giving minority religious accommodations by arguing against Biku Parekh's (and one would imagine Cohen's) position that we should consider religious practices as involuntary. He does this by appealing to the same intuitions that those in the Québec town halls made, by making a comparison to a group he does think should be given accommodations because of brute luck, the disabled. Barry is convinced that

the position of somebody who is unable to drive a car as a result of physical disability is totally different from that of somebody who is unable to drive a car because doing so would be contrary to the tenets of his or her religion. To suggest that they are similarly situated is in fact offensive to both parties. Someone who needs a wheelchair to get around will be quite right to resent the suggestion that this need should be assimilated to an expensive taste. And somebody who freely embraces a religious belief that prohibits certain activities will rightly deny the imputation that this is to be seen as analogous to the unwelcome burden of a physical disability. (Barry 2001, 37) ${ }^{8}$

My task in this paper is to answer the canonical luck egalitarian and Barry's challenge without falling into the counter-intuitive explanations that Parekh and Cohen provide about the 
involuntariness of cultural practices. My argument is a move to look beyond the choice/chance distinction rather than merely moving the cut between whether religious practices are a choice or chance toward the latter position.

\section{Diachronic Critiques of Canonical Luck Egalitarianism}

Before I begin my own argument about self-transformation and responsibility, I would like to bring out an argument that will remain implicit throughout my paper: that canonical, "static," luck egalitarianism already has a problem coming to terms with diachronic aspects of responsibility over a lifetime. Clare Chambers points out that while canonical luck egalitarians pour through the histories of individuals trying to parse what in their lives is chance and what choice, certain choices have their inegalitarian effects in the future not in the past $(2009,376)$. At some point in a person's life there is a moment that is just assumed by the canonical luck egalitarian as the point where choices should no longer be compensated for. Chambers calls this a Moment of Equal Opportunity (MEO). Chambers shows that present choices amplify their impact on the chooser's life. Correctly chosen big decisions open more opportunities while choosing wrongly, both relatively to choosing right and in an absolute sense, closes more and more opportunities. This is done in a way that disproportionately burdens the agent who made the initial choice. Instead MEOs must be done many times over a lifetime. ${ }^{9}$ Concretely, Chambers does not see how this could happen in practice. Chambers describes the dilemma thusly, "it is not at all clear how equality of opportunity can be applied throughout a person's life, since doing so poses serious problems of epistemology, efficiency and incentives, and leads to counter-intuitive results ... theories of equality of opportunity are inconsistent if they support [only one] MEO and unrealizable if they do not" $(2009,378)$. For canonical luck egalitiarians who are concerned about giving religious accommodations to minorities, there is really only one 
MEO and that is when the woman chose to veil or the man chose to wear a turban rather than a motorcycle helmet. But as Chambers points out, this hides, both, that over a life time many MEOs should be considered and also that the amplification of the cost of a single choice over time is problematic for an egalitarian theory.

Chambers has shown, as time moves forward, the costs of taking responsibility of a present choice becomes disproportionately large. Patrick Tomlin takes this and combines it with another argument about personal identity. He argues that over time, responsibility can diminish just by the fact that people should not be held responsible for their choices forever (Tomlin 2013, 400). This argument is linked to an idea of personal identity over time. 'Identity isn't enough to acquire responsibility, 'suitable reflectiveness' of agency is required too. If I am responsible because I am related to the act in a certain way then I don't see why I should be thought to be responsible at some later time unless I am still related to the act in the relevant way. If a person has changed such that whatever it was that made the action suitably reflective of their agency at the time has diminished or disappeared, then it seems plausible to think that this kind of change will diminish or extinguish responsibility" (403). This makes each present choice doubly problematic for Brute luck egalitarians: at the same time as the burdens of choosing unfairly amplify as we travel forward in time, the agent's responsibility for that action diminishes since that person's continuity with the person who made that initial choice diminishes.

This diachronic critique will be in the background as I begin my own argument against static canonical luck egalitarianism. But I do not take on all of Tomlin's argument since Tomlin (unlike Chambers) attempts to keep the choice/chance distinction by proposing a "dynamic luck egalitarianism" (Tomlin 2013, 400). There is an important difference in my argument from Tomlin's personal identity argument. This difference is that I will not be considering the case of 
just any decision that predictably and gradually becomes less of a responsibility as a person gains temporal distance from the decision. My case is a case of pious self-transformation where the link of the person before and after the transformation is strikingly different, almost a break in personal identity such that it is unpredictable, in a much shorter time, how much responsibility the pious believer has.

\section{Moving from a Third Person to a First Person View of Agency}

The big theoretical shift I would like to introduce before moving on to my argument about self transformation is a move from a third person view to the first person view of agency. Bernard Williams has a contrasting view of responsibility than the one that brute luck egalitarians use in order to support their choice/chance distinction. The objective, third person way of looking at luck that scaffolds brute luck egalitarianism, Williams calls "incident luck." The first person, agentic way of looking at luck he calls "constitutive luck." Williams finds that incident and constitutive luck problematize morality in two different ways. Incident luck undermines the idea that we can always determine before we act, which of our choices are justifiable. Constitutive luck undermines the assumption of equality regarding our capacities for moral agency (Williams 1981, 21). When looking at actions and practices of a person, luck egalitarians reflect a concern about luck's threat to autonomy. Williams, however, concentrated more on character and agency. He was more concerned about threats to a person's integrity. Considerations involved with the concept of integrity involve consistency, coherence, and commitment. Whereas for luck egalitarians, autonomy involves considerations of independence and avoiding the contamination of heteronomy. Williams's skepticism regarding the advisability of planning in advance for one's life as a whole turns on the vulnerability of the luck of our very identity. Because who we become is not immune to luck, our knowledge from now of what will 
be in our interests in the future is limited. Contingencies of our development that are inaccessible at the moment of making critical choices threaten our integrity and interfere with our carrying through on obligations and commitments. The problem of agency and integrity are such that despite the admitted contingencies and luck of our constitution, we still cannot help but feel that we should not betray commitments central to our identities. This different conception of agency makes it not only impossible to separate brute luck aspects from option luck aspects of action, but makes this separation morally irrelevant. This concentration on constitutive luck is grounded in the ethical theories of ancient philosophers such as Aristotle. What Williams, but also many religious traditions, inherit from the ancient conception of agency is that we are not born responsible but have, at most, potential for becoming agents. As Claudia Card points out, this agency is realizable to a greater or lesser extent with luck and hard work $(1996,24)$.

I emphasize this shift from backward third person to forward first person looking responsibility because when brute luck egalitarians think about religion, they look at it from the objective third person view. Additionally there is also a tendency to interpret the habitual, collective, embodied practices of religious devotion of those influenced by this first person, agentic conception as Protestantized, individual, duties of conscience. By defining religion as a matter of belief or faith, a tradition comes to be treated as "a cognitive framework, not as a practical mode of living, not as techniques for teaching the body and mind to cultivate specific virtues and abilities that have been authorized, passed on, and reformulated down the generations" (Asad 2001, 216). When religion is treated in this cognitive way, every religious believer then has complete access to their belief and can choose which among these beliefs conform to the state's general law. For example, Barry argues that the state should not accommodate ritual slaughter since if "faced with a meatless future, some Jews and Muslims 
may well decide that their faith needs to be reinterpreted so as to permit the consumption of humanely slaughtered animals" (Barry 2001, 35). Reinterpretation here is construed as an act of autonomous will that all religious believers exercise.

Contrast this view to another way of looking at religious practice, grounded in ancient philosophy. Michel Foucault argues that this ancient conception of subjectivity, reappropriating a term from Pierre Hadot (1981) called "spirituality," is the practice or exercise through which the subject carries out the necessary transformations on themselves in order to have access to religious and cultural agency. This access to religious subjectivity is not given to the subject by right. Self-transformation, self-development, modification of one's existence and to some extent becoming other than oneself are the "price to be paid" (Foucault 2005, 15) for this access. As Card argues as well, subjectivity is a kind of work. This is a work of the self on the self for which one takes responsibility in a long labour of askesis (religious practice of self-discipline) (Foucault 2005, 16) but not necessarily in knowing what exactly the outcome of this labor will be.

Brute luck egalitarians who argue against minority religious accommodations are correct that religious practices are not involuntarily compelling like coughing when you are sick. But in order to secure certain religious accommodations, those practicing veiling, wearing a turban, carrying a kirpan, and even wanting minarets in Switzerland have had to take up a type of discourse that makes religion a matter of brute luck. This reifies religion as monolithic, objective, and imposed. As Susan Mendus $(2002,34)$ argues, in order to reply to attacks by luck egalitarians, thinkers such as Biku Parekh have had to make religious practice, while not entirely beyond human control, sufficiently intractable. If we are to understand why religious people demand accommodation, we cannot just think of religion as a series of imperatives. The reasons 
that certain Muslims have for asking for accommodations for prayer at their jobs or schools cannot just be reduced to codified rules. It assumes that religions lay down certain binding rules and that the exercise of religion consists only of obeying those rules. Douglas Laycock observes bitingly, "it is as though all of religious experience were reduced to the Book of Leviticus. It is the view of religion held by many secularized adults, who left the church in their youth after hearing much preaching about sin and failing to experience any benefits" $(1990,24)$. The pietists, like the ancient Greeks, conform to particular norms not because they are obliged by universally recognized laws to do so, but because they aspire to a particular telos or ideal of self: the pious self. So we can say that the pietists are engaged in practices of self-creation through particular ways of inhabiting norms (Weir 2013, 131).

For some Muslim women, veiling is an unavoidable means to the particular end of being pious. Veiling is not the end in itself. What these women are claiming is that by not allowing them to veil, the state is frustrating a larger goal of transformation and the ability to practice their religion beyond the bare minimum. Saba Mahmood, an anthropologist who has studied veiled women in Egypt, compares the practice of veiling to a pianist who submits herself to the often painful regime of disciplinary practice, as well as to the hierarchical structures of apprenticeship, in order to acquire the ability and requisite agency to play the instrument with mastery. Her agency is predicated upon her ability to be taught, a condition classically referred to as docility (Mahmood 2005, 29). What is considered suffering under the veil actually enables certain capacities that can be exercised, for some women at least, in no other way than through the veil. One cannot simply argue that those women who choose to veil should find another way. The veil is a critical marker of piety and the ineluctable means by which she trains herself to be pious. While wearing the veil serves at first as a means to tutor herself in the attributes that make up 
piety, it is also simultaneously integral to the practice of piety: "one cannot simply discard the veil once a modest deportment has been acquired, because the veil itself is part of what defines that deportment" (158). The veil is not a mere means; it is, instead, constitutive of becoming a pious person. Piety is not a finished state, but a continuing activity. If we take the goal of the woman who veils to be a transformative activity, then taking away her veil destroys her ability to concretely become the person she chooses to be through carrying out those actions that express her own purposes and needs.

Mahmood suggests that Muslim women, regardless of whether they veil or not, in practicing to become a pious Muslim, create religious desire through a set of disciplinary acts like athletes train their body. That is to say, desire in this model is not antecedent to, or the cause of moral action, but its product $(2012,231)$. Through the use of the veil, the goal (piety) is also one of the means by which desire is cultivated and gradually made realizable. In this Aristotelian model of ethical pedagogy, external, performative acts like veiling are understood to create corresponding inward dispositions. The way the veil creates this inward disposition is through habitus. Habitus, in this older Aristotelian tradition, is understood to be an acquired excellence learned through repeated practice until that practice leaves a permanent mark on the bodily character of the person (Mahmood 2005, 136).

\section{The Problem that Self-Transformation Poses for Luck Egalitarianism}

With this, more embodied, view of the practice of veiling, it becomes harder to argue that embarking on the labor of piety is like taking a gamble where the believer "loses" if their journey leads them to a religious practice that runs afoul of general laws. Some people may go through the self-development required to access religious agency and yet will not need to veil, wear a turban, or need special accommodation to go to a mosque on Fridays. Yet inevitably there will be 
others whose self-transformation calls upon them to do one of these practices that the state does not want to accommodate. This is to say that, before they began their journey toward a more pious subjectivity, their identity might not have been complete by wearing a veil, yet somewhere along the way, they changed so much that wearing a veil turned from an option to something much more mandatory. ${ }^{10}$

What I am describing here falls somewhere between what Edna Ullmann Margalit calls a "conversion" and "drifting" toward a big decision (2006). There are two ways that the selftransformative characteristics in becoming a pious subject affects the luck egalitarian critique of minority religious accommodations. First, since piety in Islam is about training bodily habit, like drifting to a big decision, it is a subtly incremental process. It is a process such that, although the veiling subject is agential, she does not know in what way her piety will lead and whether she will end up taking up the practice of veiling in her journey toward piety. This is because her transformation will be so great, nothing other than going through and experiencing this transformation will be adequate for her to know whether her piety will or will not include veiling. Secondly, the process of bodily self-transformation is like a conversion in that it has an irrevocable quality to it.

Luck egalitarianism places such weight on the distinction between choice and chance because it assumes that the choice to become pious and then to veil fits certain paradigmatic decisional procedures that weigh the value of one's future experiences. Allowing accommodations only for those actions judged not to be a choice is supposed to disincentivize people attempting to make themselves exceptions to the law. They should not be accommodated if they choose their "expensive" lifestyle, and are therefore asking for more than their fair share. For a brute luck egalitarian, not being the exception to a general law should be an integral part of 
making the decision to become pious. To take into account the law of secularism in the public sphere and still decide to veil is considered irrational or selfish and so the individual who chooses to veil must take responsibility for their actions. The problem with this assumption is that the agent making this kind of decision is not in the epistemic condition to make this decision until after the process is over. So holding them responsible to the point of punishment is not responsibility-sensitive in the way any luck egalitarian would want.

The problem is of the epistemically impoverished starting position of anyone who would like to begin to be pious. There are two reasons for this, first is the minutely incremental nature of becoming pious and the second is the problem that piety cannot be known without going through the process of becoming pious. The decision to become a pious Muslim is not necessarily like a conversion as described by Ullman-Margalit. It is not always an instantaneous gestalt switch where one is "blinded by the light of the compelling new truth" (Ullmann-Margalit 2006, 162). This gives the process too much of a cognitive, Protestantized aspect. In reality, since it is about training the mundane, everyday habits, it is more like Ullman-Margrit's idea of "drift" decision making (170). It is only from the retroactive perspective that one could see that the self-transformation undertaken has not just been one of minute degrees, but taken altogether is a change of kind and quality (rather than quantity). Becoming pious is incremental in nature and is the continual activity of a series of small mundane decisions to change certain everyday habits without any single stage ultimately being the one where the pious woman decides to either wear or not wear the veil. The problems that Brute luck egalitarianism has with diachronic aspect of responsibility comes back to haunt it since with this kind of "drift" decision, there is no MEO to be identified. 
The problem of experience as it is related to transformative practices is illustrated well by L. A. Paul with the example of pregnancy. Paul argues that "what it's like" knowledge, such as the phenomenal knowledge a person who had never seen color might experience when seeing red for the first time, is a kind of knowledge only accessible via experience $(2015,6)$. In deciding to have a child, the mother does not know the phenomenal feeling of this experience. She does not know "what emotions, beliefs, desires, and dispositions will be caused by what it's like for her to" raise a child (7). Even if she has tried to babysit and gain experience with children in an attempt to simulate this experience and she thinks she will feel joy, there is still the lacuna in her knowledge that she still does not know what it is like to experience feeling the joy while raising the child until she actually goes through that process.

This point is further complicated in the case of religious self-transformation. In the case of pregnancy, there is an epistemically transformative experience in having and raising a child that may also include a personally transformative experience. This personal transformation is only incidental, though. For example, some parents, when they experience the epistemic transformation of raising a child may realize they do not need to change themselves. This could be because they can afford to pay others for the labour it takes to raise a child, so their activities and routines may go unchanged and they may be the same people after as they were before. But it is in the nature of working on religious piety that the self cannot remain the same. In this case, piety involves not changing to find a true "I" that was always present but dormant within, but to transcend the "I," to become different than the "I" that was (Mahmood 2005, 148). The types of bodily and emotional work one must go through to progress toward the character of a pious person involves working on one's desires. One's actions and decisions do not come from natural feeling, but instead they create them through training one's habits, memory, desire, and emotions 
(Mahmood 2005, 157). As I have argued, religion is not just a series of clear imperatives and so what one will become through self-transformation is not dictated by consulting holy texts or a religious leader. On what path she may end upon is not known at the beginning. This point is not restricted to women who veil. For instance, this type of experience of training one's self to transform is reported by Cressida Heyes in her own experience through yoga. She describes how yoga pushed her to the edge of her physical capacity while also pushing her through emotional pain, often experiencing innumerable rounds of violent sobbing. Through this bodily selfdiscipline, she felt herself change in unexpected ways, especially since yoga "isn't charted in the way that normalized discipline is: there are no leaflets or narratives or diagnoses waiting to tell me who I am and what will happen next" (Heyes 2007, 129).

This kind of bodily self-transformation constituently involves a discontinuity of the self, a change in one's beliefs, desires as well as one's cognitive and evaluative systems. This can change your personal phenomenology in deep and far reaching ways, decentering what beliefs and preferences you may have had with very different ones. This brings out the problem that these kinds of big decisions hold for Brute luck egalitarianism. How does one evaluate this kind of choice rationally? The problem for luck egalitarians with this argument is that it is different from the problem of experience in that it is not about new knowledge about the world but that we probably will not know our future personality. As Williams argued, this is the problem of constitutive luck and integrity. There must necessarily be difficulty in trying to decide for the future person you will be since, if one is training oneself to become pious correctly, there will be no continuity with that person. Yet whether that future person had a choice and is therefore responsible is predicated on the continuity of the person making the decision. This can be illustrated by Ullman-Margalit's story of the person who hesitates to have children because they 
do not want to become the boring type of personality he or she encounters in people who have had children. Yet after the experience of having children, this same person approves of their new, boring personality $(2006,167 \mathrm{n} 10)$. How do we evaluate this? If there were no child, this person would not have the new preferences, yet in having the child the old preferences seem invalid from a second-order perspective. It is not that making these kinds of self-transformative decisions is irrational since we have no clear path as to what the rational procedure would be instead. Even Brute luck egalitarians will concede that being merely causally responsible for an outcome like one billiard ball hitting another is not sufficient for agential responsibility, since the agent may reasonably have been unaware that her choice had the effect in question. One may be responsible for the foreseeable causal effects of one's choices, but one is not agent-responsible for all the causal effects of one's actions (Vallentyne 2008, 58). An agent is not broadly agent responsible for an outcome if there was no way she could have known her choice would produce the outcome since this affects an agent's disposition to choose and can thereby affect the baseline for the allocation of responsibility (Vallentyne 2011,178). Being agent-responsible is the kind of responsibility that must be focussed on when talking about minority religious accommodations since it is the one that best justifies why an agent should be forced to carry the burden of responsibility of an action.

To expect the religious agent to not take the necessary first steps in being pious because there is a chance she may or may not veil is to ask this agent to forgo everything but the minimum in practicing their religion "just in case" she may find imperative the need to wear something religiously ostentatious in the public sphere. For many believers, the attempt to distinguish what is required from what grows organically out of the religious experience is an 
utterly alien question. In most faiths, serious believers rarely concentrate their efforts on identifying the minimum that God requires (Laycock 1990, 26).

Finally, becoming pious is also "valvic" in the sense that there is an irrevocability to it. Once one puts many years of practice into piety, it is very difficult to lose the subconscious habits one has cultivated and replace them with new ones. One's habits are tied to everyday routines and the self-transformation involved in piety will alter the nature of all your relationships with others, with yourself, and with the world, in all of the practices of your daily life (Weir 2013, 133). And once one practices piety with a veil, this "training" one puts oneself through is not just about body learning but about learning a new body sense. As one of Mahmood's veiled subjects attests, while before she may have been relaxed with her hair showing, her "body literally comes to feel uncomfortable if [she does] not veil" (Mahmood 2005, 157). The telos of this bodily training is such that veiling should "attain the status of an almost physiological need that is to be fulfilled without conscious reflection" (139), ${ }^{11}$ which would explain the uncomfortable feeling when unveiled in public. This is why we must take seriously, and not assume that it is hyperbole, when we read about the Québec woman who states when asked how she would feel if a law forced her to take off her veil: “ce n'est pas banal ... ça fait partie intégrante de moi . . Si on me l'enlève, c'est comme si on m'amputait." ${ }^{\prime 2}$ There is also a normative aspect to this irrevocability. It is a conversion process in the sense that the now pious individual will look back upon their previous life in a negative light.

\section{An Objection Based on Responsibility as Identifying with One's Preferences}

While I think my argument is effective against canonical luck egalitarianism, there is still one objection open to those with strongly responsibility sensitive views of equal opportunity such as Dworkin and also Barry who do not identify with luck egalitarianism. Dworkin and 
Barry get around epistemic problems that I have just raised by arguing that we can skip the obsessive parsing of choice and chance in the history of individuals. According to Barry, "people are responsible for their preferences whenever they are content with them. How these preferences originated is irrelevant, and the ease with which they could be changed is relevant only in this way: that we would have to question the sincerity of your claim not to want to have the preferences you actually do have if it were easy to have the preferences you actually do have if it were easy for you to change" $(1991,156) \cdot{ }^{13}$ Barry finds religious belief exemplary of this principle. He thinks those in lower economic classes or with disabilities are not content and would prefer not to be in that class or have that disability and are therefore not responsible and should be allowed compensation or accommodation. But the case of a religious believer is very different since as long as you continued to be a religious believer "you could hardly complain that it was bad luck to have the preferences you had, since you would not have wished things to be any different" (Barry 1991, 157).

The problem with this idea of identifying with one's preferences causing certain responsibilities being demanded of an individual is that we do not know the scope of this responsibility. Serena Olsaretti points out that it is just assumed by luck egalitarians that preference and responsibility are tightly connected concepts that entail each other. When people with strong responsibility-sensitive views talk about their commitment to holding individuals responsible, they neglect to say what, precisely, they are committed to holding individuals responsible for. Instead, they imply that it is self-evident what the consequences of people's choices and actions are and which ones they could justifiably be held responsible (Olsaretti 2009, 169). In order to do this, we minimally need knowledge of counterfactual situations to specific actions. This is to say, when people are not responsible for something, there may not be anything 
determinate, either to be found or constructed, that they would be responsible for instead. Susan Hurley gives an example that echoes Williams's worry about constitutive luck, that, "if Sam had not had the deprived childhood that makes his current low income bad luck for him, what would he have been responsible for instead? He might have chosen to be a workaholic or a surfer, or anything in between. I call this the indeterminacy problem" (Hurley 2003, 162). There are too many things people would choose if they could, under various counterfactual conditions. So the question then becomes, is the choice of becoming pious really something that should be actively disincentivized by the state?

The way responsibility is cast by Dworkin and Barry, is that it rewards the minimally religious individual who is able to convert what little freedom she has been given to her into a higher level of satisfaction. As Joseph Heath notes, this "frugality is not rewarded because it is intrinsically good, it is rewarded because the frugal individual imposes fewer costs on others, and therefore needs to moderate her desires to a lesser degree" $(1998,185)$. To then expect her to forgo or to restrict satisfaction of that preference because it is expensive is, therefore, to ask her to accept an alienation from what is deep in her. Religious people do not regret the duties imposed on them by their reading of their religion, such as modesty in public or the extra lengths they have to go for the sake of piety, but they do regret the disadvantages that attend to their religion in the context of Western society. The point is not that religious beliefs per se are unrevisable or uncontestable, but that resource considerations provide the wrong sorts of grounds for motivating people to revise their religious beliefs or their commitment to their community (McGann 2012, 13).

My argument here against Dworkin and Barry is a species of argument called the Harshness objection (see Voigt 2007) used against those who define responsibility as 
identification with preferences. To only be able to practice the bare minimum just in the case this leads to a conflict that needs an accommodation is too harsh a penalty to inflict. The irony of the harshness objection is that as one begins to identify more deeply with one's preference, according to Barry and Dworkin, one gains more and more responsibility for that preference yet it also makes the cost of that responsibility more and more harsh. As David Miller argues against Barry's comparison of religious practice with disability, "the opportunity to do X, in other words, is not just the physical possibility of doing X. At the very least, it is the possibility of doing X without incurring excessive costs" $(2002,51)$. As Tomlin points out, as an egalitarian, one cannot be monomaniacal about responsibility-sensitivity because we should remember its pro tanto nature $(2013,397)$. And therefore Carl Knight concedes that the brute luck/ option luck distinction cannot carry all the justificatory load. This highlights "the possibility that egalitarian justice, especially as depicted by Dworkin, treats the bearers of valuational judgment-based expensive tastes in unduly harsh fashion" $(2009,497)$.

\section{Getting Beyond Choice/Chance}

Again, I emphasize, the argument presented here should not be taken to show that although it is intuitive that we think certain minority religious practices like veiling are a choice, that veiling is really unchosen and is therefore brute luck and should be accommodated. This assumes that the chance/choice distinction held here is the appropriate view of egalitarianism. The argument presented is meant to trouble this distinction. I can agree with those at Québec town halls or Brian Barry that this practice of veiling did not "happen" to these women. Practicing veiling is not an involuntary action nor is culture reified enough that it "causes" them to veil. These women's agency was integral throughout the process. One might even say, through 
their self-discipline they were able to increase and unlock new capacities that extend their agency.

But in having to defend the veil as a choice, it becomes impossible for women who veil to articulate, in a way that is intelligible to the secular public, the fact that the practice of veiling is indispensable to their religiosity and their sense of self because these are seen as inimical to each other. My point is that Brute luck egalitarianism is not able to cover the type of agency expressed by women who veil and this is not just about being descriptively wrong in an academic sense. By rendering veiled women's distinct configuration of agency conditioned by authority unintelligible, they open approaches of critiquing these religious practices that should not be legitimate. In France for instance, ${ }^{14}$ the argument was made that "there are a thousand ways for a Muslim woman who aspires to wear the veil to wear it on the inside without wearing it on the outside" (Fernando 2010, 26). This kind of argument draws on the assumption that the relationship between conscience and practice is a semiotic relationship of signification. For them, religious practices like veiling are outward manifestations of an already constituted conscience. According to this logic, banning a practice does not constitute a violation of religious liberty because it has no effect on the believer's conscience. If I had relied on a theory of transformation based just on phenomenal and experiential transformation rather than self-transformation as a disciplined, embodied work, the door might have been reopened for this kind of choice/chance argument. The inner, cognitive belief becomes involuntary and unchangeable and therefore inviolable but a religion's external manifestations are variable, optional and chosen and therefore do not have to be accommodated. Not relying on cognitivist assumptions makes a difference in the real world because it is this logic of unchosen internal belief versus chosen external 
manifestation of religiosity that is used the European Court of Human Rights (ECHR) to justify not overturning bans on veiling in France, Switzerland, and Turkey. ${ }^{15}$

Finally, one might justifiably ask how we can think about minority religious accommodation without choice/chance or internal/external belief to arbitrate which accommodations are legitimate and which are not? The first step in making this gestalt switch is to stop thinking of this issue as one of accommodation at all. The language of "accommodation" is not part of a theory of justice but implies what Anna Galeotti terms a modus vivendi, a pragmatic compromise, which can be accorded today and denied tomorrow, a concession of discretionary power $(2002,43)$. This lack of secureness in their ability to pursue their religious ends means that minority groups will begin to lack confidence in the majority's capacity or willingness to be responsive to their concerns and so there is a failure of trust (Carens and Williams 1998, 168). A concentration on which accommodations the majority should allow hides the history of exclusion of the minority in question either because they are latecomers on the scene, or because they were previously oppressed or invisible. So these conflicts of accommodation (veiling, wearing a turban on a motorcycle, Sikh child taking a knife to school, kosher/halal slaughter of animals etc.) are not actually about deep moral disagreement but rather concern asymmetries in social standing, status, respect, and public recognition (Galeotti 2002, 5). These conflicts then precipitate negative majoritarian perceptions of traits, habits, and practices of minority groups which are singled out as "different" and excluded from what the majority defines as standard forms of behaviour (Galeotti 2002, 10).

Jeremy Waldron asks us to consider certain practices from a different view than the majority. Take for example, the situation where some children get together with an older adult and he supplies them with alcohol. What about the situation where a priest passes a cup of wine 
to young communicants. Are these the same action or different actions? A man is found in a public place with a knife concealed on his person. Is this knife a dangerous and offensive weapon? Or does it belong to a Sikh, carrying a kirpan, in fulfillment of religious obligation (Waldron 2002, 4)? The first is understood by most in the West as part of a recognized, innocuous everyday occurrence, while the second is usually considered an accommodation. It is not just that religious minorities should be allowed accommodations because there is a history of oppression but because otherwise the practices of religious minorities will never be integrated into the unproblematic traditions of the majority. There have been accusations that multicultural minority traditions are too rigid and closed off from "liberatory" norms of Western culture. Yet if we continue to talk about "allowing" religious practices as "accommodations" for religious minorities, Western tradition becomes rigid and not open to the inscription of different norms as part of "our" heritage. Because the event of communion is entwined with Western tradition such that it becomes a background practice, allowing underaged children to consume wine is considered natural rather than as an "accommodation" to the equality of law. There is no hyperbole that this may become a gateway to alcohol addiction and that we must paternally take these children's safety into consideration first. Yet this is the kind of discourse that surrounds the case of Sikh's wanting to wear turbans instead of motorcycle helmets. The rationale that Québec and Italy ${ }^{16}$ give to why they allow a large cross to adorn Québec's parliament and Italy's schools, yet must ban all other religious symbols from public office, is that the cross is part of Québec and Italy's patrimony. Yet if we take the case of the history of Jews in Québec, their history and traditions are entwined with Québec's for over a hundred years. Why should the Jewish kippah then not be considered as just another part of Québec's patrimony? How long does it take for “their" traditions turn into "our" traditions? 


\section{$\underline{\text { Works Cited }}$}

Arneson, Richard J. 2000. “Luck Egalitarianism and Prioritarianism.” Ethics 110, no. 2: 339349.

Arneson, Richard J. 2007. "Does Social Justice Matter? Brian Barry's Applied Political Philosophy." Ethics 117, no. 3: 391-412.

Asad, Talal. 2001. "Reading a Modern Classic: W. C. Smith's 'The Meaning and End of Religion"” History of Religions 40, no. 3: 205-222.

Barry, Brian. 2001. Culture And Equality: An Egalitarian Critique Of Multiculturalism. Cambridge, Mass.: Harvard University Press.

Card, Claudia. 1996. The Unnatural Lottery: Character And Moral Luck. Philadelphia, PA: Temple University Press.

Carens, Joseph H., Melissa S. Williams. 1998. "Muslim Minorities in Liberal Democracies: The Politics of Misrecognition." In Secularism And Its Critics. Ed. Rajeev Bhargava. Delhi: Oxford University Press.

Chambers, Clare. 2009. "Each Outcome Is Another Opportunity: Problems with the Moment of Equal Opportunity." Politics, Philosophy \& Economics 8, no. 4: 374-400.

Cohen, G.A. 2004. "Expensive Tastes Rides Again." In Dworkin and His Critics: With Replies by Dworkin, edited by Justine Burley. Malden, MA: Blackwell Pub.

Dworkin, Ronald. 2004. "Ronald Dworkin Replies." In Dworkin and His Critics: With Replies by Dworkin, edited by Justine Burley. Malden, MA: Blackwell Pub.

Dworkin, Ronald. 1981. "What is Equality? Part 2: Equality of Resources." Philosophy \& Public Affairs, 10, no. 4, 283-345.

Fernando, Mayanthi L. 2010. "Reconfiguring Freedom: Muslim Piety and the Limits of Secular Law and Public Discourse in France." American Ethnologist 37, no. 1: 19-35.

Foucault, Michel. 2005. The Hermeneutics Of The Subject: Lectures At The College De France, 1981-1982. Trans. Frederic Gros. New York: Palgrave-Macmillan.

Galeotti, Anna E. 2002. Toleration as Recognition. Cambridge: Cambridge University Press.

Heath, Joseph. 1998. "Culture: Choice or Circumstance?.” Constellations 5, no. 2: 183-200.

Heyes, Cressida J. 2007. Self Transformations: Foucault, Ethics, And Normalized Bodies. Oxford: Oxford University Press.

Hurley, Susan L. 2003. Justice, Luck, And Knowledge. Cambridge, Mass.: Harvard University Press.

Knight, Carl. 2009. "Egalitarian Justice and Valuational Judgment.” Journal of Moral 
Philosophy 6: 482-98

Laycock, Douglas. 1990. “The Remnants of Free Exercise.” The Supreme Court Review: 1-68.

Mahmood, Saba. 2012. "Ethics and Piety." In A Companion to Moral Anthropology, edited by Didier Fassin. Hoboken: Wiley- Blackwell, 223-241.

Mahmood, Saba. 2005. Politics of Piety: The Islamic Revival And The Feminist Subject. Princeton, N.J.: Princeton University Press.

McGann, Michael. 2012. "Equal Treatment and Exemptions: Cultural Commitments and Expensive Tastes." Social Theory and Practice 38, no. 1: 1-32.

Mendus, Susan. 2002. "Choice, Chance and Multiculturalism." In Multiculturalism Reconsidered: 'Culture And Equality' And Its Critics, edited by P. J. Kelly. Cambridge: Polity Press.

Miller, David. 2002. "Liberalism, Equal Opportunities and Cultural Commitments." In Multiculturalism Reconsidered: 'Culture and Equality' and Its Critics, edited by P. J. Kelly. Cambridge: Polity Press.

Olsaretti, Serena. 2009. "Responsibility and the Consequences of Choice." Proceedings of the Aristotelian Society, 109, no. 1 pt. 2: 165-188.

Paul, L.A. 2015. "What you Can't Expect When You're Expecting.” Res Philosophica 92, no. 2: $1-23$.

Rakowski, Eric. 1991. Equal Justice. Oxford: Clarendon Press.

Sharadin, Nathanial. 2015. "How You Can Reasonably Form Expectations When You're Expecting." Res Philosophica 92, no. 2: 1-12

Tan, Kok-Chor. 2008. “A Defense of Luck Egalitarianism.” The Journal of Philosophy 105, no. 11: $665-90$.

Taylor, Charles, and Gerard Bouchard. 2008. Building the Future: A Time for Reconciliation Report. Québec: Commision de Consultation sure Les Pratiques D'Accommodement Reliees Aux Difference Culturalles.

Tomlin, Patrick. 2013. "Choices Chance and Change: Luck Egalitarianism Over Time.” Ethical Theory and Moral Practice 16: 393-407.

Ullmann-Margalit, Edna. 2006. "Big Decisions: Opting, Converting, Drifting." Royal Institute of Philosophy Supplement 58, May: 157-172.

Valenta, Markha. 2012. "Pluralist Democracy or Scientistic Monocracy?: Debating Ritual Slaughter." Erasmus Law Review 5, no. 1: 27-41

Vallentyne, Peter. 2008. "Brute Luck and Responsibility." Politics, Philosophy \& Economics 7, no. 1: $57-80$. 
Vallentyne, Peter. 2011. "Responsibility and False Beliefs.” In Responsibility and Distributive Justice, edited by Carl Knight and Zofia Stemplowska. Oxford: Oxford University Press.

\author{
Voigt, Kristin. 2007. "The Harshness Objection: Is Luck Egalitarianism Too Harsh on the \\ Victims of Option Luck?" Ethical Theory and Moral Practice 10: 389-407.
}
Weir, Allison. 2013. Identities And Freedom: Feminist Theory Between Power And Connection. Oxford: Oxford University Press.
Williams, Bernard Arthur Owen. 1981. Moral Luck: Philosophical Papers, 1973-1980. Cambridge: Cambridge University Press.

\title{
Endnotes:
}

\footnotetext{
1 "Bill 60: Charter Affirming the Values of State Secularism And Religious Neutrality And The Equality Between Women And Men, And Providing A Framework For AccommodationRequests," http://www.assnat.qc.ca/en/travaux-parlementaires/projets-loi/projet-loi-60-40-1.html

2 " 5 . In the exercise of their functions, personnel members of public bodies must not wear objects such as headgear, clothing, jewelry or other adornments which, by their conspicuous nature, overtly indicate a religious affiliation."

${ }^{3}$ See Valenta 2012.

${ }^{4}$ I will use both these terms interchangeably.

${ }^{5}$ Many canonical luck egalitarian theories will replace the word "choice" with "responsibility," while Dworkin and Barry will replace "choice" with "preference."

${ }^{6}$ A perfect example of this canonical view is Eric Rakowski who denies Cohen's portrayal of expensive tastes that were cultivated when young as involuntary. Before these beliefs became deep beliefs, and even if these beliefs are deep, if the agent "engendered this interest and permitted it to become pronounced, aware of the costs . . . then it seems only right that [they] should answer for [their] choice" (Rakowski 1991, 56). He concludes that "to the extent that people elect to expose themselves to, preserve, or suppress certain desires, the more or less expensive preferences they develop are beyond the bounds of justice: no correction need or should be made for them" (1991, 57).

${ }^{7}$ In his article on Barry's final book, Why Social Justice Matters, Arneson summarizes Barry's strong responsibility-sensitive views of equal opportunity. "In the language of personal responsibility, Barry's view is that, if people start with equal opportunities and some voluntarily undertake courses of action from this equal starting point that leave them worse off than others, the loss that falls on the individual in consequence of such voluntary choice is her responsibility. It is not the responsibility of society to make good the loss" (Arneson 2007, 397).

${ }^{8}$ I will not critique here the ableist assumptions of this kind of example.

${ }^{9}$ This is something Dworkin makes clear in his critique of "starting gate theories" (1981,310) yet as I will get to, Chambers still has him in a dilemma.

${ }^{10}$ Mayanthi Fernando, an anthropologist who works with veiled women in France after the veil ban reports that "the temporal gap between beginning to pray and beginning to veil was common to most of the practicing Muslim women I knew, who prayed regularly for months and sometimes years before putting on the headscarf. Such a gap highlights the intellectual and bodily disciplinary process through which these young Muslim women worked on themselves by undertaking one step in a series of necessary practices to induce the desire for the next step toward becoming a properly pious Muslim" (Fernando 2010, 25).

${ }^{11}$ This particular quote is in reference to daily prayer, but Mahmood makes it clear that this applies to wearing the veil as well.

12 "It is not trivial ... [The veil] is an integral part of me ... If one were to remove it, it would be like an amputation." http://www.lapresse.ca/le-soleil/opinions/chroniqueurs/201309/19/01-4691194-vous-etes-comme-desreligieuses.php

${ }^{13}$ Dworkin expresses this argument very simply and in a negative way, "a "taste" is a handicap [due accommodation and compensation] if one would prefer not to have it" $(2004,392 \mathrm{n} 31)$.
} 
${ }^{14}$ Although this originates in France, there have been similar arguments made in support of headscarf bans in other countries

${ }^{15}$ See Dogru v. France; Dahlab v. Switzerland ; and Leyla, Sahin v. Turkey

${ }^{16}$ See Lautsi and Others v. Italy 